\title{
n-Dodecylbenzene Sulfonic Acid (DBSA) as a Novel Brønsted Acid Catalyst for the Synthesis of Bis(indolyl)methanes and Bis(4-hydroxycoumarin-3-yl)methanes in Water
}

\author{
Balu Pawar ${ }^{1}$, Vinod Shinde ${ }^{2}$, Atul Chaskar ${ }^{1^{*}}$ \\ ${ }^{1}$ Department of Chemistry, Sanghavi College of Engineering, Nashik, India \\ ${ }^{2}$ Pacific Academy of Higher Education \& Research University, Udaipur, India \\ Email: *achaskar25@gmail.com
}

Received February 12, 2013; revised March 14, 2013; accepted March 22, 2013

Copyright (C) 2013 Balu Pawar et al. This is an open access article distributed under the Creative Commons Attribution License, which permits unrestricted use, distribution, and reproduction in any medium, provided the original work is properly cited.

\begin{abstract}
n-Dodecylbenzene sulfonic acid (DBSA) as a novel, biodegradable, and efficient Brønsted acid catalyst used for the reaction of indoles/4-hydroxy coumarin with aldehydes to obtain a bis(indolyl)methanes/bis(4-hydroxycoumarin-3yl)methanes, respectively. The catalyst exhibited remarkable activity, and tolerated a wide variety of functional groups providing the desired bis(indolyl)methanes and bis(4-hydroxycoumarin-3-yl)methanes in good to excellent yield (70\% $96 \%$ ) in water.
\end{abstract}

Keywords: n-Dodecylbenzene Sulfonic Acid (DBSA); Indole; Aldehyde; Bis(indolyl)methane; Bis(4-hydroxycoumarin-3-yl)methanes

\section{Introduction}

Heterocyclic compounds, the highly popular precursor molecules are extensively employed in food, cosmetic and pharmaceutical industries for their broad range of biological activities [1-3]. In pharmaceutical industries coumarin, indole and their derivatives have received great attention due to their therapeutic potential for antibiotic, anti-inflammatory, anti-coagulant, analgesic, antitumor, anti-HIV, anti-apoptotic, cytotoxic, anti-oxidant and insecticidal activities [4-12]. Moreover bis(indolyl) methane derivatives are used as sensors for $\mathrm{Cu}^{2+}$ ions [13]. Bis(indolyl)methanes and bis(4-hydroxycoumarin3 -yl) methanes are obtained by the condensation of two molecules of indoles or 4-hydroxy coumarin with one molecule of aldehyde or ketone in the presence of a Lewis acid or Brønsted acid catalyst. Literature reports revealed that the Lewis acid catalysts are deactivated or decomposed by the presence of nitrogen in the reactants. Hence, it necessitates having more than stoichiometric amounts of Lewis acid in the reaction mixture [14].

Hitherto, numbers of methods are in use for synthesis of all these biologically active molecules [15-23]. Some

${ }^{*}$ Corresponding author. of these methods show advantages with respect to each other. Many of these protocols require stoichiometric and expensive catalyst, prolonged reaction time, high temperature, harsh reaction conditions use of organic solvents, tedious and laborious workup procedure, etc. The failure in removal of water formed during the course of reaction leads to low yields of products.

Nowadays, with the awareness towards the environment, researchers are emphasizing on finding out the methods that will fulfill the criteria of environment friendly green chemistry methodologies. In this line, very recently, Thakur et al. [24] used phosphate-impregnated titania catalyst under solvent free condition. Kalita and co-workers [25] used Indion Ina $225 \mathrm{H}$ resin for synthesis of bisindolyl methane. In our recent work, we have used silica supported sodium hydrogen sulfate and Indion 190 resin for the synthesis of bis(4-hydroxycoumarin-3yl)methanes [26].

Performing the reactions in micellar media instead of organic solvents can alter the reaction rates and the pathways of the reactions. Due to the "local concentration effect" Micelles can concentrate the reactants within their small volumes, stabilize substrates, intermediates or products and orient substrates. A reactant may align at the 
interface in a "surfactant-like" manner and a water-soluble species will preferentially attack at the polar end while an oil-soluble species at the apolar end of the reactant. Therefore, we may control the reaction rates, mechanism; regio- and stereo-chemistry in the presence of micellar media [27-30].

In this context, we are trying to design a protocol that uses micellar media in aqueous condition [31-33]. Present work underlines the effectiveness of micellar media in synthesis of bis(indolyl)methanes and bis(4-hydroxycoumarin-3-yl)methanes (Scheme 1).

\section{Results and Discussion}

The initial efforts were devoted towards investigation of the best catalyst. We screened various Lewis acids, brønsted acids and surfactants to check the catalyst efficiency for condensation of indole and benzaldehyde. Interestingly, among the catalysts tested, DBSA was found to be the best catalyst with regards to reaction time and yield of the product (Table 1). Further, we extended same protocol for synthesis of bis(4-hydroxycoumarin-3-yl) methanes.

In order to elucidate the role of the DBSA as catalyst, a control reaction was set up using indole $(2 \mathrm{mmol})$ and benzaldehyde $(1 \mathrm{mmol})$ in water in the absence of catalyst. The control reaction offered low amounts of bis (indolyl)methanes after 24 hours (Table 1, Entry 1). However, $p$-Toluenesulfonic acid (TsOH) and boric acid afforded the products in quantitative yield after 3 and 6 hours, respectively (Table 1, Entries 2, 3). Surfactant in water formed a white turbid reaction mixture indicating that the long chain of the surfactant is necessary for the formation of the colloidal dispersion. Beside this, it was found that the type of surfactant used, influenced both, yield and reaction time. The surfactant like CTAB, SDS and Triton X-100 were found to be less effective for the formation of bis(indolyl)methanes (Table 1, Entries 4 7). While in combination of $\mathrm{TsOH}$ and sodium dodecyl sulfate (SDS) which formed a colloidal dispersion gave the adduct with significant yield (Table 1, Entry 9). Observations revealed that DBSA is the most efficient surfactant catalyst for this reaction. The enhancement in rate and yield was observed owing to the successful removal

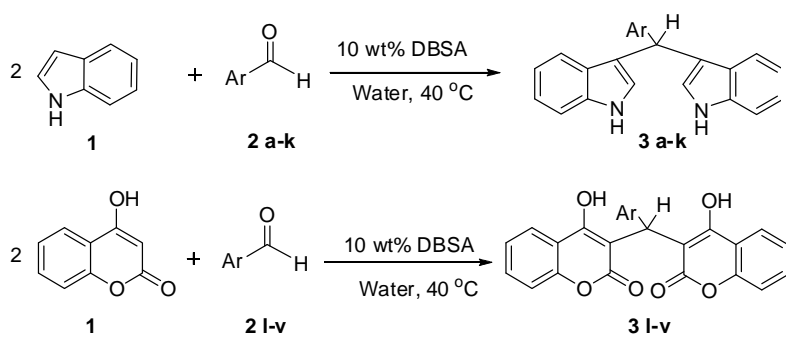

Scheme 1. Synthesis of bis(indolyl)methanes/bis(4-hydroxycoumarin-3-yl)methanes.
Table 1. Optimization of the catalyst for the synthesis of bis (indolyl)methanes in water ${ }^{\mathrm{a}}$.

\begin{tabular}{cccc}
\hline Entry & Catalyst & Time (h) & Yield $^{\mathrm{b}}(\mathbf{\%})$ \\
\hline 1 & - & 24 & 13 \\
2 & $p$-TsOH (10 wt\%) & 3 & 66 \\
3 & Boric acid (10 wt\%) & 6 & 52 \\
4 & SDS (10 wt\%) & 12 & 31 \\
5 & CTAB (10 wt \%) & 12 & 30 \\
6 & TBAB (10 wt \%) & 12 & 28 \\
7 & Triton X - 100 (5 wt \%) & 12 & 35 \\
8 & Triton X - 100 (10 wt\%) & 3 & 60 \\
9 & p-TsOH + SDS (10 wt\%) & 1.5 & 82 \\
10 & DBSA (5 wt \%) & 1 & 80 \\
11 & DBSA (10 wt $\%)$ & 1 & 91 \\
12 & DBSA (15 wt $\%)$ & 1 & 70 \\
\hline
\end{tabular}

${ }^{\mathrm{a}}$ Reaction condition: Indole $(2 \mathrm{mmol})$, benzaldehyde $(1 \mathrm{mmol})$, micelle $(5$ $\mathrm{mL}), 40^{\circ} \mathrm{C}$; ${ }^{\mathrm{b}}$ Isolated yield.

of water molecule generated during the course of reaction by hydrophobic interior of micelles.

Indeed, concentration of the catalyst also plays vital role in the synthesis of Bis (indolyl) methanes. After varying the concentration of DBSA, we got optimum yield with $10 \mathrm{wt} \%$ of catalyst. On further increasing the amount of catalyst, the yield of corresponding product decreased (Table 1). We attributed this to the micelles ability of forming a mask around its own micelle at high concentration which could lead to the inhibition of substrate interactions.

In order to appraise feasibility and scope of this protocol, structurally diverse aldehydes were treated with indole and 4-hydroxycoumarin at the optimized conditions to furnish bis(indolyl)methanes and bis(4-hydroxycoumarin-3-yl)methane derivatives, respectively (Table 2). The products were obtained in good to excellent yields and characterized by ${ }^{1} \mathrm{H}$ NMR, ${ }^{13} \mathrm{C}$ NMR and physical con- stant. Physical and spectral data of known compounds are in accordance with those reported in the literature [20-26].

\section{Conclusion}

In conclusion, we have demonstrated that DBSA is an excellent catalyst for the reaction of indoles/4-hydroxy coumarin with aromatic aldehydes to get bis(indolyl) methanes/bis(4-hydroxycoumarin-3-yl)methane derivatives in water. High activity and easy handling makes DBSA as an ideal catalyst for this transformation. The procedure has the advantages of mild reaction conditions, high yields of products, short reaction time, and simple experimental technique, making it a useful and attractive process for the synthesis of bis(indolyl)methane and bis (4-hydroxycoumarin-3-yl)methane derivatives. 
Table 2. Synthesis of bis(indolyl)methanes and bis(4-hydroxycoumarin-3-yl)methanes ${ }^{\mathrm{a}}$.

(1)

${ }^{a}$ Reaction condition: Indole $(2 \mathrm{mmol}) / 4$-hydroxy coumarin, aldehyde (1 mmol), DBSA (10 wt $\%)$, water $(5 \mathrm{~mL}), 40^{\circ} \mathrm{C}$, Time: $1 \mathrm{hr}$; ${ }^{b}$ Isolated yield.

\section{Experimental}

\subsection{Materials and Methods}

All commercial reagents were used as received without purification and all solvents were reagent grade. The reaction was monitored by TLC using $0.25 \mathrm{~mm}$ E-Merck silica gel 60 F254 precoated plates, which were visualized with UV light. Melting points were taken in open capillaries. The IR spectra were recorded on a PerkinElmer 257 spectrometer using $\mathrm{KBr}$ discs. ${ }^{1} \mathrm{H}$ NMR and ${ }^{13} \mathrm{C}$ NMR spectra were recorded on a VXR-300 MHz instrument using TMS as an internal standard.

\subsection{General Procedure}

Indole or 4-hydroxycoumarin $(2 \mathrm{mmol})$ and benzaldehyde $(106 \mathrm{mg}, 1 \mathrm{mmol})$ were added to $5 \mathrm{~mL}$ of water containing $10 \mathrm{wt} \%$ of DBSA. The reaction mixture was stirred for $1 \mathrm{~h}$ at $40^{\circ} \mathrm{C}$. The progress of the reaction was monitored by TLC. After $1 \mathrm{~h}, 10 \mathrm{~mL}$ of ethyl acetate and $5 \mathrm{~mL}$ of water was added to the reaction mixture. The product was extracted in ethyl acetate layer, washed with small quantity of water, dried over sodium sulfate, and evaporated under vacuum to get crude product. The crude product obtained was further purified using column chromatography by eluting with ethyl acetate: hexane $(2: 8)$ solvent system.

\subsection{Physical and Spectral Data}

\section{Compound (3a):}

${ }^{1}$ H NMR: (DMSO- $\left.d_{6}\right): \delta 5.86(\mathrm{~s}, 1 \mathrm{H}), 6.64(\mathrm{~d}, J=2.26$ $\mathrm{Hz}, 2 \mathrm{H}), 7.00-7.57$ (m, 13H), 8.45 (brs, 2H, NH, exchangeable with $\left.\mathrm{D}_{2} \mathrm{O}\right)$.

${ }^{13}$ C NMR: (DMSO- $\left.d_{6}\right): \delta 31.2,110.5,111.0,118.1$, $119.7,121.0,123.8,126.0,127.4,128.3,128.6,136.8$, $144.7 \mathrm{ppm}$.

IR (KBr): 3390, 3060, 2980, 1610, 1600, 1460, 1110.

Mp: $105^{\circ} \mathrm{C}$ (Lit. $104^{\circ} \mathrm{C}-105^{\circ} \mathrm{C}$ );

Compound (3I):

${ }^{1}$ H NMR: (DMSO- $\left.d_{6}\right): \delta 6.20(\mathrm{~s}, 1 \mathrm{H}), 6.90-7.50(\mathrm{~m}$, $13 \mathrm{H}), 11.07$ (s, $2 \mathrm{H},-\mathrm{OH}$, exchangeable with $\mathrm{D}_{2} \mathrm{O}$ ).

${ }^{13}$ C NMR: (DMSO- $\left.d_{6}\right)$ : $\delta 16.0,91.0,105.2,108.1$, $116.0,117.3,124.0,125.4,126.1,127.0,128.7,130.0$, $132.5,140.0,163.1,166.3$.

IR (KBr): 3032, 1655, 1609, 754.

Mp: $229^{\circ} \mathrm{C}\left(\right.$ Lit. $\left.228^{\circ} \mathrm{C}-230^{\circ} \mathrm{C}\right)$.

\section{REFERENCES}

[1] J. Hinman, H. Hoeksema, E. L. Caron and W. G. Jackson, "The Partial Structure of Novobiocin (Streptonivicin)," Journal of the American Chemical Society, Vol. 78, No. 5, 1956, pp. 1072-1074. doi:10.1021/ja01586a055

[2] R. O'kenne and R. D. Thomes, "Coumarins: Biology Application and Modes of Action," Wiley \& Sons, Chich- 
ester, 1997.

[3] M. Zahradnik, "The Production and Application of Fluorescent Brightening Agents," Wiley \& Sons, Chichester, 1982.

[4] M. A. Stahmann, I. Miyoshi and L. K. Paul, "3-Substituted 4-Hydroxycoumarin and Process of Making it," US Patent 2427578, 1947.

[5] R. D. H. Murray, J. Mendez and S. A. Brown, "The Natural Coumarins," Wiley, Chichester, 1982.

[6] R. J. Sundberg, "The Chemistry of Indoles," Academic, New York, 1970.

[7] M. Lounasmaa and A. Tolvanen, "Simple Indole Alkaloids and Those with a Nonrearranged Monoterpenoid Unit," Natural Product Reports, Vol. 17, 2000, pp. 175191. doi:10.1039/a809402k

[8] S. Hibino and T. Choshi, "Simple Indole Alkaloids and Those with a Nonrearranged Mono Terpenoid Unit," Natural Product Reports, Vol. 18, 2001, pp. 66-87. doi:10.1039/b004055j

[9] T. R. Garbe, M. Kobayashi, N. Shimizu, N. Takesue, M. Ozawa and H. Yukawa, "Indolyl Carboxylic Acids by Condensation of Indoles with $\alpha$-Keto Acids," Journal of Natural Products, Vol. 63, No. 5, 2000, pp. 596-598. doi:10.1021/np990517s

[10] R. Bell, S. Carmeli and N. Sar, "Vibrindole A, a Metabolite of the Marine Bacterium, Vibrio Parahaemolyticus, Isolated from the Toxic Mucus of the Boxfish Ostracion Cubicus," Journal of Natural Products, Vol. 57, No. 11, 1994, pp. 1587-1590. doi:10.1021/np50113a022

[11] T. Osawa and M. Namiki, "Structure Elucidation of Streptindole, a Novel Genotoxic Metabolite Isolated from Intestinal Bacteria," Tetrahedron Letters, Vol. 24, No. 43, 1983, pp. 4719-4722. doi:10.1016/S0040-4039(00)86237-1

[12] X. Guinchard, Y. Vallee and J.-N. Denis, "Total Synthesis of Marine Sponge Bis(indole) Alkaloids of the Topsentin Class," The Journal of Organic Chemistry, Vol. 72, No. 10, 2007, pp. 3972-3975. doi:10.1021/jo070286r

[13] R. Martinez, A. Espinosa, A. Tarraga and P. Molina, "Bis(indolyl)methane Derivatives as Highly Selective Colourimetric and Ratiometric Fluorescent Molecular Chemosensors for $\mathrm{Cu}^{2+}$ Cations," Tetrahedron, Vol. 64, No. 9, 2008, pp. 2184-2191. doi:10.1016/j.tet.2007.12.025

[14] S. Kobayashi, M. Araki and M. Yasuda, "One-Pot Synthesis of $\beta$-Amino Esters from Aldehydes Using Lanthanide Triflate as a Catalyst," Tetrahedron Letters, Vol. 36, No. 32, 1995, pp. 5773-5776.

[15] J. S. Yadav, B. V. Subba Reddy, C. V. S. R. Murthy, G. Mahesh Kumar and C. Madan, "Lithium Perchlorate Catalyzed Reactions of Indoles: An Expeditious Synthesis of Bis(indolyl)methanes," Synthesis, Vol. 5, 2001, pp. 783-787. doi:10.1055/s-2001-12777

[16] S. A. Sadaphal, K. F. Shelke, S. S. Sonar and M. S. Shingare, "Ionic Liquid Promoted Synthesis of Bis(indolyl) Methanes," Central European Journal of Chemistry, Vol. 6, No. 4, 2008, pp. 622-626. doi:10.2478/s11532-008-0069-5

[17] H. Hagiwara, M. Sekifuji, T. Hoshi, K. Qiao and C. Yo- koyama, "Synthesis of Bis(indolyl)methanes Catalyzed by Acidic Ionic Liquid Immobilized on Silica (ILIS)," Synlett, Vol. 8, 2007, pp. 13200-1322. doi:10.1055/s-2007-977453

[18] S. A. Sadaphal, S. S. Sonar, M. N. Ware and M. S. Shingare, "Cellulose Sulfuric Acid: Reusable Catalyst for Solvent-Free Synthesis of Bis(indolyl)methanes at Room Temperature," Green Chemistry Letters and Reviews, Vol. 1, 2008, pp. 191-196.

[19] S.-R. Sheng, Q.-Y. Wang, Y. Ding, X.-L. Liu and M.-Z. Cai, "Synthesis of Bis(indolyl)methanes Using Recyclable PEG-Supported Sulfonic Acid as Catalyst," Catalysis Letters, Vol. 128, 2009, pp. 418-422.

[20] S. Qadir, A. A. Dar and K. Z. Khan, "Synthesis of Biscoumarins from 4-Hydroxycoumarin and Aromatic Aldehydes - A Comparative Assessment of Percentage Yield under Thermal and Microwave-Assisted Conditions," Synthetic Communications, Vol. 38, No. 20, 2008, pp. 34903499. doi:10.1080/00397910802162942

[21] M. Kidwai, V. Bansal, P. Mothsra, S. Saxena, R. K. Somvanshi, S. Dey and T. P. Singh, "Molecular Iodine: A Versatile Catalyst for the Synthesis of Bis(4-hydroxycoumarin) Methanes in Water," Journal of Molecular Catalysis A: Chemical, Vol. 268, 2007, pp. 76-81.

[22] J. M. Khurana and S. Kumar, "Tetrabutylammonium Bromide (TBAB): A Neutral and Efficient Catalyst for the Synthesis of Biscoumarin and 3,4-Dihydropyrano[c] chromene Derivatives in Water and Solvent-Free Conditions," Tetrahedron Letters, Vol. 50, No. 28, 2009, pp. 4125-4127. doi:10.1016/j.tetlet.2009.04.125

[23] H. Mehrabi and H. Abusaidi, "Synthesis of Biscoumarin and 3,4-Dihydropyrano[c]chromene Derivatives Catalysed by Sodium Dodecyl Sulfate (SDS) in Neat Water," Journal of the Iranian Chemical Society, Vol. 7, 2010, pp. 890-894.

[24] D. Talukdar and A. J. Thakur, "A Green Synthesis of Symmetrical Bis(indol-3-yl)methanes Using PhosphateImpregnated Titania Catalyst under Solvent Free Grinding Conditions," Green Chemistry Letters and Reviews, Vol. 6, 2013, pp. 55-61.

[25] R. Surasani, D. Kalita and K. B. Chandrasekhar, "Indion Ina $225 \mathrm{H}$ Resin as a Novel, Selective, Recyclable, EcoBenign Heterogeneous Catalyst for the Synthesis of Bis(indolyl)methanes," Green Chemistry Letters and Reviews, Vol. 6, 2013, pp. 113-122.

[26] V. Padalkar, K. Phatangare, S. Takale, R. Pisal and A. Chaskar, "Silica Supported Sodium Hydrogen Sulfate and Indion 190 Resin: An Efficient and Heterogeneous Catalyst for Facile Synthesis of Bis-(4-hydroxycoumarin-3-yl) Methanes," Journal of Saudi Chemical Society, 2012. doi:10.1016/j.jscs.2011.12.015

[27] T. Dwars, E. Paetzold and G. Oehme, "Reactions in Micellar Systems," Angewandte Chemie International Edition, Vol. 44, 2005, pp. 7174-7179.

[28] F. M. Menger and C. E. Portnoy, "Chemistry of Reactions Proceeding Inside Molecular Aggregates," Journal of the American Chemical Society, Vol. 89, No. 18, 1967, pp. 4698-4703. doi:10.1021/ja00994a023

[29] J. H. Fendler and E. J. Fendler, "Catalysis in Micellar and 
Micromolecular System," Academic Press, New York, 1975.

[30] S. Tascioglu, "Micellar Solutions as Reaction Media," Tetrahedron, Vol. 52, No. 34, 1996, pp. 11113-11152. doi:10.1016/0040-4020(96)00669-2

[31] A. Chaskar, V. Padalkar, K. Phatangare, B. Langi and C. Shah, "Miceller-Mediated Phosphomolybdic Acid: Highly Effective Reusable Catalyst for Synthesis of Quinoline and Its Derivatives," Synthetic Communications, Vol. 40, No. 15,2010 , pp. 2336-2340. doi: $10.1080 / 00397910903245141$

[32] B. Pawar, V. Padalkar, K. Phatangare, S. Nirmalkar and A. Chaskar, "Miceller Media Accelerated Baylis-Hillman Reaction," Catalysis Science \& Technology, Vol. 1, No. 9, 2011, pp. 1641-1644. doi:10.1039/c1cy00278c

[33] K. Phatangare, V. Padalkar, K. Murugan and A. Chaskar, "Brønsted Acid-Surfactant (BAS) Catalysed Cyclotrimerization of Aryl Methyl Ketone," Current Chemistry Letters, Vol. 1, 2012, pp. 133-138. 